\title{
Differences and similarities in motivation for offline and online eSports event consumption
}

\author{
Florian Neus \\ University of Siegen \\ florian.neus \\ @uni-siegen.de
}

\author{
Frederic Nimmermann \\ University of Siegen \\ frederic.nimmermann \\ @ uni-siegen.de
}

\author{
Katja Wagner \\ University of Siegen \\ katja.wagner \\ @uni-siegen.de
}

\author{
Hanna Schramm-Klein \\ University of Siegen \\ schramm-klein.hanna \\ @uni-siegen.de
}

\begin{abstract}
ESports is a rising phenomenon that attracts followers worldwide. Recently, big eSports events are hosted regularly as a counterpart to the "traditional" online streams. However, the differences between offline and online consumption have not been scientifically addressed. Based on the Motivation Scale for Sports Consumption (MSSC), on-site visitors and stream followers $(N=637)$ of a big eSports event were surveyed. By analyzing the motives for eSports consumption of these two groups, insights about users following one specific broadcast form were derived and success factors (e.g. intention to visit) were assessed.

While on-site attendees are motivated by social aspects, online participants seek knowledge gain and are interested in details of the gameplay. Escape and drama motivation are equally important for both groups. The findings give new insights in the field of eSports and help practitioners develop live experiences of eSports online as well as offline.
\end{abstract}

\section{Introduction}

Roughly defined as "a form of sports where the primary aspects of the sport are facilitated by electronic systems", eSports is already a key phenomenon of the modern digital area [21]. Organized in leagues and ladders around different games of various genres, eSports is a very successful business venture and still growing year by year [13]. Through streaming options on various platforms (e.g. twitch.tv or youtube.com), eSports can be consumed by users all over the world [61]. These streams are extremely popular amongst eSports fans and are often consumed by millions of users [13]. Additionally, eSports events, often hosted in big arenas and stadiums, allow thousands of eSports fans, who are willing to leave the purely digital environment of the internet, to consume eSports content in a completely new setting [20]. Where users were previously constrained to consume eSports alone at home in front of their personal computer, they now fill arenas to watch their favorite team compete on stage [21]. Hence, the digital barriers and limitations have vanished, and the overall experience has been enhanced to fulfill aspects of traditional events. The basic content, following two or more teams competing in a digital environment, remains the same for the event as well as the stream. Nevertheless, many of the surrounding factors do vary and might change the overall experience. Thus, the question arises how users are choosing a means of consumption, and what motivates them to attend the event on-site or follow the given stream online. Answering these questions is of importance especially for streaming service design (e.g. chat possibilities, custom camera views or other personalization options) and marketing potential.

Research, thus far, has focused on a variety of aspects of general eSports consumptions but did not deal with the different forms of eSports consumption. Macey and Hamari [36], Hallmann [20] and Heere [24] offered classification approaches of eSports with respect to other phenomena, as well as traditional sports, arguing for its general importance and overall influence for society. The general consumption motivation of eSports has been assessed by Hamari and Sjöblom [21], who developed a motivation scale that especially caters to eSports. Furthermore, Pizzo et al. [40], as well as Donghun and Schoenstedt [12], have analyzed the differences between sports and eSports consumption. Surprisingly, a comparison of the previously described two forms of eSports consumption has not yet been made. Yet, literature regarding general sports consumption indicates possible differences between different forms of consumption which is predominantly indicated through differences in the motivation to follow the event [26, 45, 62]. Thus, to get a more profound view on differences between both consumptions' forms and therefore, be able to derive implications, our first research question reads as follows. 
RQ1: What differences can be observed in the motivation of onsite participants and online participants of eSports events?

Moreover, studies have indicated that these differences might also impact important aspects of event success [62]. Relevant factors like satisfaction with the event and a corresponding attitude towards the experience might, therefore, also be subject to the different forms of consumption. Thus, to get a more thorough view that goes beyond the differences in motivation regarding the event success, we strive to answer the following second research question in the context of esports events:

RQ2: What differences can be observed in the attitude towards the event and the satisfaction with the event?

By answering those two research questions, our study will widen the available research in the field of eSports consumption and assess the differences in offand online consumption of eSports. To find explanatory ground for our research, we conducted a study at a league of legends event in Berlin. In the following, we will present the fundamentals of our research, the results of the study and derive implications for management and research.

\section{Literature review and hypothesis development}

\subsection{Motivation to attend}

General motivations to attend events have been studied for several years and researchers have been keen on understanding the different groups of attendees to better cater to their needs. Uysal, Gahan and Martin [50] were among the first to develop a scale that dealt with the different dimension of event attendees' motivation. Building on that initial scale, Formica and Uysal [15] identified different groups of visitors at a festival in Italy. Later, Backman et al. [3] identified differences among age and gender when assessing the motivations of event attendees. Versions of the scale, furthermore, were adapted to various settings and tested at numerous events, showing its general usefulness to describe the event participation motivation. Generally, the type of event was found to play a significant role when examining the motivation of event attendees and researchers have successfully adjusted the motivational scale to fit the event in question $[34,59]$. Moreover, Trail and James [49] adapted the scale to measure the general motivation for sport consumption. Their results showed that the motivational traits of general sport consumption were relatable to the motivation of event attendees. In a similar fashion, and important for our context, Hamari and Sjöblom [21] adjusted the motivation scale to be applicable to eSports. Their version was employed in our study. We utilize their adjusted version of the MSSC to derive answers to our research questions. In the following, we will hypothesize the proposed connection and differences between the given consumption forms regarding the different dimension of motivation.

Firstly, events have always been about the interaction of people with one another. Often, groups of friends or family will attend an event together and use the provided content as a platform for their social interaction with each other [29, 41]. This is something that also holds true for eSports in general [21]. Nowadays, technology allows for interaction with other users in virtual places. Streaming platforms, e.g. twitch.tv have integrated features that allow contact with other individuals while consuming a given eSports stream [5, 44]. Therefore, the basic possibility of interaction is provided in both consumption scenarios. However, researchers have argued that the virtual interaction with peers or family is often seen as a substitute for real life interaction [45]. Users of streams could certainly be interested in using interaction features of provided platforms, but the social connection is much more relatable to a real-life interaction, provided by event. Hence, we argue that there will be differences in offline and online eSport consumption in the social dimensions of motivation.

H1: The social motivation will be significantly higher for offline participants.

Next to the socialization with other visitors or users of a given eSports event, the perceived social connection to the players is also an important motivational factor for (e)sport consumption. Experiencing a victorious achievement and celebrating the success of a favorite player is considered to be an important motivational factor of all sport spectators [11, 14, 17]. When comparing the two consumption possibilities of eSports, one can argue that the offline consumption allows for a stronger connection with other fans and spectators, while the online consumption enhances the perceived connection to victorious players. eSports has been an online phenomena and most active players are still using websites, social media and other virtual communities to present themselves [21, 46]. Events are a sort of exception to these normal representations, that are hosted irregularly and sometimes far away from specific fans [47]. Nonetheless, fans of specific players will be able to follow their favorite team or player online. Given 
a successful game, their fan-based perceived connection will, as it does in most sports, lead to a perceived level of combined success, where the victory will in turn be perceived as a personal achievement [21, 55, 56]. Attendees of the event will certainly not be free of this motivational dimension, but the perceived achievement of online users will be, based on this reasoning, significantly higher:

H2: The achievement dimension will be significantly higher for online participants.

Moreover, gaining knowledge has been proven to be a relevant factor for sport consumption. Attending any form of sporting event does generally offer different forms of knowledge acquisition. One aspect can be found in the possibility of attendees to inform themselves about the venue, players and teams [17, 58]. Furthermore, information about the sport in general, e.g. tactics or play styles, can be obtained by attendees [27]. Users following the stream, or people attending the event, are also highly likely to be playing the given game themselves. Experiencing other (professional) players playing the game offers the possibility to extend their own degree of knowledge about the game and possible strategies and tactics. Both dimensions should, therefore, be expected to influence any form of eSports consumption.

However, Hamilton et al. [22] have discussed the importance of knowledge sharing in online media consumption settings and stated that new streaming platforms offer enormous potential to exchange expertise about the given issue. This should be a key difference between the two consumption forms, leading to different ways of game portrayal. People at the event will most likely not be as close to the action as streaming users. Building on additional features of twitch and similar websites, users are enabled to follow the action intensively and learn about the game, the players' tactics and strategies. Therefore, we assume that the motivation to obtain knowledge will be significantly higher for stream users:

\section{H3: The knowledge dimension will be significantly higher for online participants.}

In addition, experiencing the skillset of players is another dimension of (e)sport motivation and, generally, means to do so are provided online and offline [40]. However, the provided features of streaming platforms exceed the event attendees' point of view in the arena. Where event attendees are, by design, forced to follow a broader overview of the game and the related action, stream users are enabled to follow the game closely and appreciate the skillset of players [52, 57]. The implemented platforms even allow users to switch between different viewpoints, enabling them to exclusively follow individual players and obtain a better understanding of their tactics. Therefore, the motivation to appreciate the skillset of the involved players will be significantly higher for online participants.

\section{H4: The skills dimension will be significantly higher for online participants.}

Another aspect of the game, that motivates potential spectators is the aesthetic demonstration of players. Relating to the elegance or excellence of the given sport, this motivational trait is especially influential in very visual sports that allow spectators to observe a detailed form of sport [21]. Therefore, sports that allow, or even generally include the judgement of strong visual elements, e.g. gymnastics, are commonly considered to attract viewers with a strong aesthetic motivation [14, 49, 55]. Here, Hamari and Sjöblom [21] found that eSport consumption was negatively influenced by the aesthetic motivation of users. They argued that the basic link between this motivational dimension and the eSport consumption was very well given, but that the form of utilization as well as the game genre in question would play an important role. In deference to traditional forms of sport, most games played feature long and intensive battles. Therefore, the possibility to enjoy and observe given specifics of the players' skillset are rather limited. Other forms of sport, e.g. gymnastics or golf, do offer a relaxed setting that allows spectators to observe the performance of a single athlete while most games played in eSports are based on interaction of two or more teams with almost no break. Given rules and interaction of players, therefore, limit the possibilities of spectators to focus on a single player's performance. Nevertheless, a general possibility of enjoying an aesthetic performance is certainly given in both forms of consumption and build on the discussed advantages of the existing platforms. One example of these eSport aesthetics might be the players' performance with the mouse and keyboard, i.e. the so-called (and often depicted) actions per minute. However, these actions need close ups of the players' hands, which are more usually broadcast within streams (e.g. by picture in picture), whereas the offline consumption, i.e. the big screen at the event, mostly focuses on the actual gameplay. Thus, we argue that the online participants will show a significantly higher aesthetic motivation based on the consumption possibilities:

H5: The aesthetics dimension will be significantly higher for online participants. 
Moreover, based on previous research into sports event consumption, we argue that an escape from daily routines is another dimension of motivation. The content observed is used as a distraction from problems and issues that might bother the individual [17]. Sports consumption in general, and eSports consumption specifically, have proven to cater for this dimension of motivation [21, 49]. Offline and online consumption of eSports events should, therefore, be able to provide possibilities for escapism to users and attendees alike. However, recent research shows that the actual environment of consumption impacts the overall experience $[45,46]$. Thus, consuming a stream at home might be less effective in creating an escape perception, because the environment (e.g. in front of a pc or television) is still like other daily experiences. On the other hand, visiting an event on-site (e.g. arena) offers new and as yet unknown impressions and thus, should be sought by consumers with a more distinct desire for escape. Hence, we hypothesize:

H6: The escape dimension will be significantly higher for offline participants.

Moreover, the drama of a given match is another dimension of motivation and might be very similar to the previous dimension in the case of the impact of an offline event. Drama refers to the uncertain outcome of games. A close game that offers a lot of excitement to viewers is a key element of (e)sport consumption [40, $41,49]$, since the content provided offline and online is identical and allows both groups to experience the game and its outcome. However, drama might be interpreted as multidimensional and thus, should be affected by more influential factors than just the outcome of a given match. For instance, the overall atmosphere in an arena with thousands of spectators following an extremely thrilling game situation should intensify the perceived drama. Similar results can be observed, for example, in research into basketball or other forms of sport consumption $[8,62]$. Thus, eSports enthusiasts with a more distinct need for drama, should seek offline event participation:

H7: The drama dimension will be significantly higher for offline participants.

\subsection{Attitude and satisfaction}

The attitude towards the event has been identified as a key factor to explain event-related behavior and measure the overall success of events [37]. Especially in regard of sponsoring effects, the attitude towards the event and the related brand has proven to be of significant influence $[6,42]$. Therefore, eSports events and offerings should be keen on understanding the influential factors of attitude towards the event and how it is related to the form of consumption [36, 46]. Hence, we argue that the attitude towards an eSports event is also an important factor to assess when analyzing the different consumption forms. Gursoy et al. [19] introduced the concept of two dimensional attitude towards a given event. With the distinction of utilitarian and hedonic aspects, they argue, the different factors of event consumption can better be described this way[19]. Similar approaches have also been brought forward in digital environments where Salehan et al. [43] have found reasoning that both these dimensions are also relevant to explain the behavior of users in social networking services.

Hedonic attitude of event consumption relates to aspects of enjoyment and perceived fun yielded through the given event [19]. These aspects may be perceived differently from individual to individual, but a general understanding that this dimension plays a vital part in explaining attitude towards a given event is assumed [19]. In digital environments, hedonic attitude has been connected to self-enhancing and joyful experiences, that are also perceived individually [51]. In particular, research into social networking sites has addressed this issue and concluded that the social features (e.g. connecting with other users) are very relevant to explain the perceived enjoyment of involved users [43]. In regard to electronic gaming, research has also identified social interaction to play a vital role in explaining the hedonic attitude of users [43]. As previously stated, the environmental setting of offline consumption will enhance the perceived connection of attendees. Therefore, we argue that the overall attitude towards the event will be significantly higher for offline participants:

H8: The hedonic attitude will be significantly higher for offline participants.

Utilitarian factors relate to the possibility of event attendees or stream users utilizing the experience to their advantage [19]. In digital environments, e.g. social networking sites, users tend to advance their career by connecting with possible employers online, or sharing and gathering job-related information [43]. Furthermore, users tend to visit utilities websites as a source of knowledge that enhances their private or professional life [2]. Similar effects can be expected in regard of streaming options of eSports events. Websites are conceived as a tool that enable users to enhance their personal or private life. Therefore, users' utilitarian attitude towards the event will be higher for online participants as their focus of consumption will be 
strongly connected to factors such as knowledge gain and aesthetic appreciation to enhance their own skillset:

H9: The utilitarian attitude will be significantly higher for online participants.

Moreover, event related satisfaction has been considered to be connected to the game and the service satisfaction [30, 60]. Game-related satisfaction would be tangible in both consumption forms, while service satisfaction would certainly be conceived differently in both settings. Yoshida and James [60] argue that the atmosphere is a strong indicator for overall satisfaction. Within online environments the satisfaction might, therefore, be related to the community and their connection with one another, but real perceived atmosphere is only conceivable within offline forms of

consumption [48]. Therefore, we postulate:

H10: The satisfaction with the event will be significantly higher for offline participants.

\subsection{Behavior}

Forthcoming event success is highly related to positive behavioral intention of visitors. Through their revisiting intention, they can positively influence the long-term success of events. Kim et al. [30] found that revisiting intentions are strongly related to the experiences made while attending the event. Therefore, we assume that either form of consumption will lead to visiting intentions of the participants. Furthermore, we argue that event attendees on site will show more intention to visit the event on-site again, while online consumers will show more interest in watching another streamed version of an eSports event.

H11: The intention to visit an event on site will be significantly higher for offline participants.

H12: The intention to consume a stream of the event will be significantly higher for online participants.

\section{The empirical study}

\subsection{Measures and procedures}

To test our hypotheses, we prepared a questionnaire for the EU LCS Event in Berlin in early 2018. Riot Games, organizer of the event, offered exclusive live coverage of the event through lolsports, youtube and twitch.tv. However, the actual content (i.e. the video stream) was similar on all three websites. The same applies, for instance, to the interaction possibilities (e.g. chat), so that these three websites can be classified as highly comparable. The coverage included commentated gaming content as well as shots from inside the event venue. This is a standard form of eSport online event coverage and provides the desired background for our study. In accordance with the language spoken at the event and in the online stream, the survey was conducted in English. Hence, everyone following the stream was able to take part in our survey. By utilizing international, game-related message boards (e.g. reddit and twitter) to reach online participants, we furthermore ensured that a representative, international sample could be drawn. On-site participants were randomly approached with a similar paper and pencil version of the questionnaire.

At the beginning of the questionnaire participants were asked what form of consumption they had chosen, i.e. on-site or online consumption, to ensure that participants could be unequivocally assigned to either one of the two groups. Moreover, participants were clearly instructed to only access the previously selected event form to guarantee a high degree of discriminatory power.

In addition to demographics, we used measures that related to the postulated hypotheses. The motivational dimensions were operationalized in accordance with Hamari and Sjöblom [21] who adapted the MSSC of Trail and James [49] to the eSports genre.

Both dimensions of attitude were measured with five items each, taken from Gursoy et al. [19]. Satisfaction with the event was adapted from Voss et al. [53]. Intentions were measured with one item taken from Wakefield [54]. The measurement was performed using well established multi-item scales with a seven-point Likert scale and all reflective constructs satisfy the Cronbach's Alpha threshold of $>0.70$. The final sample, both on-site and online, consisted of $\mathrm{N}=637$ participants (81.7 \% male, mean age $\mathrm{M}=21.40$, standard deviation $\mathrm{SD}=5.59)$. Of these, online viewers: $\mathrm{n}=482$ respondents $(86.9 \%$ male, age $\mathrm{M}=21.01, \mathrm{SD}=$ 4.65), and on-site participants: $n=155$ respondents $(34,9 \%$ female, age $\mathrm{M}=22.73, \mathrm{SD}=7.79)$.

\subsection{Results and discussion}

To verify our hypotheses, we used multiple t-tests with on-site (i.e. offline) participation form and online consumption via stream as independent variables. The reason for choosing t-tests is that research has shown ttests to be robust against violation of statistical requirements (e.g. different group sizes or non-normal distribution) [20, 47]. In addition, as we are comparing two groups, i.e. offline versus online consumption, using t-tests seems appropriate. Table 1 shows the 
Table 1. Hypothesis testing.

\begin{tabular}{|c|c|c|c|}
\hline Dependent Variable & Mean (SD) & t-Value (p-Value) & Hypothesis \\
\hline \multicolumn{4}{|l|}{ Motivation to attend } \\
\hline Social & $\begin{array}{l}\text { Online: } 4.32(1.70) \\
\text { Offline: } 4.75(1.76)\end{array}$ & $T(633)=2.721(p=.007)$ & $\mathrm{H} 1 \checkmark$ \\
\hline Achievement & $\begin{array}{l}\text { Online: } 5.08(1.55) \\
\text { Offline: } 4.78(1.77)\end{array}$ & $T(633)=2.086(p=.037)$ & $\mathrm{H} 2 \checkmark$ \\
\hline Gain Knowledge & $\begin{array}{l}\text { Online: } 5.95(1.05) \\
\text { Offline: } 5.46(1.30)\end{array}$ & $T(633)=4.761(\mathrm{p}<.001)$ & $\mathrm{H} 3 \checkmark$ \\
\hline (Physical) Skills & $\begin{array}{l}\text { Online: } 6.52(0.75) \\
\text { Offline: } 6.19(1.14)\end{array}$ & $\mathrm{T}(633)=4.028(\mathrm{p}<.001)$ & $\mathrm{H} 4 \checkmark$ \\
\hline Aesthetics & $\begin{array}{l}\text { Online: } 5.56(1.29) \\
\text { Offline: } 5.08 \text { (1.49) }\end{array}$ & $T(633)=3.873(p<.001)$ & H5 $\checkmark$ \\
\hline Escape & $\begin{array}{l}\text { Online: } 4.57(1.47) \\
\text { Offline: } 4.70(1.67)\end{array}$ & $T(633)=.923(p=.357)$ & H6 $x$ \\
\hline Drama & $\begin{array}{l}\text { Online: } 6.16(1.03) \\
\text { Offline: } 6.04(1.27)\end{array}$ & $T(633)=1.171(p=.242)$ & $\mathrm{H} 7 \times$ \\
\hline \multicolumn{4}{|l|}{ Attitude and Satisfaction } \\
\hline Hedonic Attitude & $\begin{array}{l}\text { Online: } 6.19(0.96) \\
\text { Offline: } 6.18(1.18)\end{array}$ & $T(633)=0.012(p=.990)$ & $\mathrm{H} 8 \times$ \\
\hline Utilitarian Attitude & $\begin{array}{l}\text { Online: } 5.26(1.09) \\
\text { Offline: } 5.31 \text { (1.08) }\end{array}$ & $T(633)=.512(p=.609)$ & $\mathrm{H} 9 x$ \\
\hline Satisfaction with the Event & $\begin{array}{l}\text { Online: } 5.65(1.10) \\
\text { Offline: } 6.00(1.21)\end{array}$ & $T(633)=3.364(p=.001)$ & $\mathrm{H} 10 \checkmark$ \\
\hline \multicolumn{4}{|l|}{ Behavior } \\
\hline Attend Offline & $\begin{array}{l}\text { Online: } 2.16(1.69) \\
\text { Offline: } 4.41(2.06)\end{array}$ & $\mathrm{T}(633)=13.588(\mathrm{p}<.001)$ & $\mathrm{H} 11 \checkmark$ \\
\hline Attend Online & $\begin{array}{l}\text { Online: } 6.21(1.18) \\
\text { Offline: } 5.69(1.86)\end{array}$ & $\mathrm{T}(633)=4.007(\mathrm{p}<.001)$ & $\mathrm{H} 12 \checkmark$ \\
\hline
\end{tabular}

results of our analysis. Results show a significant difference in almost all variables under review. Most hypotheses can be validated through the derived results.

Firstly, regarding the motivation we mostly observe the expected tendencies. Here, the social dimension is more pronounced in case of offline events. This dimension can, therefore, be considered as more relevant in an offline environment and are more likely to be supported by a traditional form of event consumption, i.e. meeting friends and family at an event. However, social interaction cannot be described as the primary driver of consumption, as it tends to be less important in comparison to the remaining dimensions. Thus, also interesting is the result in terms 
of knowledge gain and the observation of player's skills. Both dimensions are more distinctive of stream consumption. The latter might be explained by the details within the digital stream, i.e. player close ups and direct screen capturing directly on the screen at home, which enables the consumers to follow the matches in detail. In comparison, offline participants, who can "only" follow the match on a huge canvas, do not get that level of detail. This assumption might also be supported by taking the results of the aesthetic dimension into consideration. Nonetheless, it should be mentioned that while all the dimensions differ significantly, the size of the effect is rather small.

Surprisingly, we do not find any effect regarding the Attitude dimensions towards the event. Generally, the data shows that the event, in both consumption forms, is considered to yield hedonic as well as utilitarian features. For hedonic, $M=6.19$ and 6.18 and for utilitarian, $\mathrm{M}=5.26$ and 5.31 (online vs. offline, respectively), the overall values for hedonic attitude are more pronounced in comparison to the derived values of utilitarian attitude. eSports is, first of all, based on a game that obviously is being played for the enjoyment it yields. Nevertheless, the high value for utilitarian attitude demonstrates that eSports also offers a lot of useful aspects to its fans. In accordance to the data received for the motivational subscales that relate to utilitarian aspects (e.g. knowledge gain), the analysis generally indicated these factors to be of importance. Prior research indicated that most events and products can very well cater to both dimensions of attitude, and our research supports those claims $[4,19]$. Nonetheless, the proposed differences between the two consumption methods cannot be observed, leading to the assumption that the overall attitude towards the event manifests on a different level and is not directly determined by the chosen form of consumption.

As hypothesized, the satisfaction with the event does in fact differ among the two forms of consumption. Generally, the perceived satisfaction of the participants is relatively high in both groups, indicating a positive reaction to the event. Building on the argument and research of Yoshida and James [60], we argued that the atmosphere and surrounding factors (e.g. form of broadcast in the arena) have a more positive influence on the level of satisfaction than the surrounding factors of online consumption. Here, satisfaction in regard to digital experiences is generally considered to be highly dependent on the surrounding factors that users create for themselves [1]. Therefore, the possibilities for event organizers concerning streaming options are limited to the utilized platform. Everything else is ultimately left to the users' own efforts to enhance the experience. On the other hand, the factors influencing event satisfaction for visitors on-site are much more tangible for the organizers [60]. Event-related research has indicated numerous factors that, directly or indirectly, influence the perceived satisfaction with the event, all of which can and should be addressed by the event organizers $[8$, 30].

Regarding the behavior of the participants, we see differences in both variables examined. While both groups intend to watch another event online, participation in an offline event reveals a different result. Offline participants would tend to participate again, whereas the results show that online participants would continue to stick to the stream only. Online streaming has become easily accessible for almost everyone with a fast enough internet connection [5, 7]. Hence, there are few obstacles to witness another eSports event online. Fans of the game and the event series will always be interested in witnessing another event. Streaming certainly seems to be perceived as the more convenient option. However, on-site event participation does offer additional features of personal connection and atmosphere, but the main consumption method for most attendees and followers seems to remain within the digital environment.

\section{Conclusion}

\subsection{Summary of findings}

Overall, we were able to identify differences as well as similarities between both forms of consumption. The differences in motivation to consume provide further proof of the strengths and weaknesses of eSports events and streams. Keen observers and fans of the game, who are interested in playing themselves, seem to favor the streaming option, just to be able to examine the action closely. Events offer more emotional fans a great outlet for social interaction. Nevertheless, similarities in attitude and some motivation dimension prove that the general perception of the event does not differ significantly between the two groups.

Attending events on-site and following a given stream online, based on our data, cannot be considered a substitute for each other. Each consumption method offers advantages, based on slightly differently motivated visitors and consumers. Given that even important outcome variables (e.g. satisfaction) differ for both forms of consumption, it is important to address the advantages of each form and cater to their strengths. These lead to interesting research questions and implications for managers. 


\subsection{Implications and limitations}

Building on recent research results in the fields of eSports, event-marketing, and online environment, our research helps to widen the existing literature in this new field of interest. eSports is a global and rising phenomenon with unique features that need to be addressed. The derived differences of both forms of consumption indicate that the motivational dimensions related to performance and the game itself were significantly higher for online participants. The question arises as to what characterizes these participants. Similar research into Chinese table tennis matches, for example, has determined that online participants demonstrate stronger feelings of fanship with players [62]. Further examination of the participants should, therefore, be addressed in further research.

Moreover, our study was conducted at a League of Legends event in Berlin and online. Due to this setting, some limitations arise. eSports includes numerous games of different genres [47]. Therefore, it is highly likely that the derived results should differ when assessing a different game from a different genre (e.g. tactical shooter like Overwatch or Counter-Strike). Event type has been found to play a vital role in traditional event-related research, and similar aspects could be connected to the game played when dealing with eSports [10,30].

In this context it should also be mentioned that geographical and economic limitations might affect the present results $[3,9]$. The latter could explain why, on the one hand, we find significant differences between offline and online eSports consumption motivation, but on the other only observe relatively small effect sizes. Here, event observers who answered the questionnaire regarding online participation might have an eSport motivation, which would lead to the conclusion that those gamers prefer on-site consumption. However, due to considerable economic expense (for example the cost of traveling from their own country, potentially a long way from the event), simply cannot participate offline. Hence, further research could address this issue and investigate the impact of an offline consumption willingness in context of a "forced" online participation, i.e. stream.

Our sample portrays a common issue regarding eSports research. Most of the players and followers, thus far, are male [23]. Although the issue of gender has been addressed by eSports-related research [18, 28], the male dominance of participation limits the possibilities to fully assess this influential factor. The derived sample fully represents the underlying gender distribution and provides sufficient explanatory power for the conducted study.
Although the literature argues for a connection between motivational factors and the attitude towards an event, our results show that the effect of the consumption form is only given in the motivational factors. Event-related research has, thus far, only assessed the motivational factors of event visitation [3, $31,32]$ or argued for the value of attitude to explain sponsorship effectiveness and other phenomena $[6,33$, $37,38]$. Future research endeavors should try to connect these issues and learn about the interplay of these two constructs.

Human behavior in social live streaming services has been assessed through several studies, addressing factors such as platform representation, identification and interaction with streamers, and consumer expectations [5, 39, 44]. Assumptions derived from these studies build on the usage of twitch and similar platforms to follow an individual or a given company. The special aspects of event consumption (i.e. eSports event consumption) has not yet been addressed.

Finally, social factors were among the few aspects of motivation that demonstrated stronger values for offline participation. Modern streaming platforms offer numerous options to communicate with other users (i.e. through direct message or chat), but these options are not yet fully capable of replacing real life experiences [5, 25, 44]. Lim et al. [35] evaluated the influence of the perceived psychological distance of streaming users, and their research indicates that there are a few things that platform designers could implement to strengthen the perceived tie of users. Accordingly, eSports managers could possibly enhance the social experience of users when streaming the given event. Through group offerings, special chat rooms, and more interactive features the perceived social connection of users could be enhanced.

Another aspect of possible social interaction could be seen in the connection between players and their fans. The received data also indicated that the players, their skillset, and the possibility of knowledge gain are advantageous features of online consumption. These aspects could also be enhanced by a more personal connection between players and the audience. Seeing that these aspects seem to be of importance to eSport fans, additional offerings that allow for a more personal and intense interaction of attendees, users, and the players should lead to positive reactions from fans [47, 57]. Research has indicated that stream followers are often interested in a personal connection with the streamer and that the perceived connection can also enhance positively related features (e.g. trust or fanship) $[16,26,61]$. Due to the digital origins of eSports and its tie to the streaming community, the personality of players should be considered an asset that needs to be addressed more by event organizers. 


\section{References}

[1] Anderson, R.E. and S.S. Srinivasan, "E-satisfaction and e-loyalty: A contingency framework", Psychology \& Marketing, 20(2), 2003, pp. 123-138.

[2] Ardichvili, A., V. Page, and T. Wentling, "Motivation and barriers to participation in virtual knowledge-sharing communities of practice", Journal of Knowledge Management, 7(1), 2003, pp. 64-77.

[3] Backman, K.F., S.J. Backman, M. Uysal, and K.M. Sunshine, "Event Tourism: An Examination of Motivations and Activities", Festival Management and Event Tourism, 3(1), 1995, pp. 15-24.

[4] Batra, R. and O.T. Ahtola, "Measuring the hedonic and utilitarian sources of consumer attitudes", Marketing Letters, 2(2), 1991, pp. 159-170.

[5] Bründl, S., C. Matt, and T. Hess, "Consumer use of Social Live Streaming Services: The Influence of CoExperience and Effectance on Enjoyment", in Proceedings of the 25th European Conference on Information Systems (ECIS), Guimarães, Portugal. 2017.

[6] Carrillat, F.A., B.A. Lafferty, and E.G. Harris, "Investigating sponsorship effectiveness: Do less familiar brands have an advantage over more familiar brands in single and multiple sponsorship arrangements?", Journal of Brand Management, 13(1), 2005, pp. 50-64.

[7] Chen, C.-C. and Y.-C. Lin, "What drives live-stream usage intention? The perspectives of flow, entertainment, social interaction, and endorsement", Telematics and Informatics, 35(1), 2018, pp. 293-303.

[8] Chen, C.-Y., Y.-H. Lin, and H.-T. Chiu, "Development and psychometric evaluation of sport stadium atmosphere scale in spectator sport events", European Sport Management Quarterly, 13(2), 2013, pp. 200-215.

[9] Chung, W. and C.W. Woo, "The effects of hosting an international sports event on a host country: The 2008 summer Olympic Games", International Journal of Sports Marketing and Sponsorship, 12(4), 2011, pp. 2-21.

[10] Crompton, J.L. and S.L. McKay, "Motives of visitors attending festival events", Annals of Tourism Research, 24(2), 1997, pp. 425-439.

[11] Dale, B., J. van Iwaarden, T. van der Wiele, and R. Williams, "Service improvement in a sports environment: A study of spectator attendance", Managing Service Quality: An International Journal, 15(5), 2005, pp. 470-484.

[12] Donghun, L. and L.J. Schoenstedt, "Comparison of eSports and Traditional Sports Consumption Motives", ICHPER-SD Journal of Research, 6(2), 2011, pp. 39-44.

[13] https://newzoo.com/insights/articles/esports-revenueswill-reach-696-million-in-2017/, accessed 4-24-2018.

[14] Fink, J.S., G. Trail, and D.F. Anderson, "Environmental Factors Associated with Spectator Attendance and Sport Consumption Behavior: Gender and Team Differences", Sport Marketing Quarterly, 11, 2002.

[15] Formica, S. and M. Uysal, "A Market Segmentation of Festival Visitors: Umbria Jazz Festival in Italy", Festival Management and Event Tourism, 3(4), 1995, pp. 175-182.
[16] Friedländer, M.B., "Streamer Motives and UserGenerated Content on Social Live-Streaming Services", Journal of Information Science Theory and Practice, 5(1), 2017, pp. 65-84.

[17] Gantz, W. and L.A. Wenner, "Fanship and the Television Sports Viewing Experience", Sociology of Sport Journal, 12(1), 1995, pp. 56-74.

[18] Gray, P.B., J. Vuong, D.T. Zava, and T.S. McHale, "Testing men's hormone responses to playing League of Legends: No changes in testosterone, cortisol, DHEA or androstenedione but decreases in aldosterone", Computers in Human Behavior, 83, 2018, pp. 230-234.

[19] Gursoy, D., E.R. Spangenberg, and D.G. Rutherford, "The Hedonic and Utilitarian Dimensions of Attendees' Attitudes Toward Festivals", Journal of Hospitality \& Tourism Research, 30(3), 2006, pp. 279-294.

[20] Hallmann, K. and T. Giel, "eSports - Competitive sports or recreational activity?", Sport Management Review, 2017.

[21] Hamari, J. and M. Sjöblom, "What is eSports and why do people watch it?", Internet Research, 27(2), 2017, pp. 211-232.

[22] Hamilton, W.A., O. Garretson, and A. Kerne, "Streaming on twitch", in Conference proceedings of the 32nd Annual ACM Conference on Human Factors in Computing Systems, M. Jones, P. Palanque, A. Schmidt, and T. Grossman, Editors, the 32nd annual ACM conference, Toronto, Ontario, Canada. 2014. Assoc. for Computing Machinery: New York, NY.

[23] Hartmann, T. and C. Klimmt, "Gender and Computer Games: Exploring Females' Dislikes", Journal of ComputerMediated Communication, 11(4), 2006, pp. 910-931.

[24] Heere, B., "Embracing the sportification of society: Defining e-sports through a polymorphic view on sport", Sport Management Review, 21(1), 2018, pp. 21-24.

[25] Hilvert-Bruce, Z., J.T. Neill, M. Sjöblom, and J. Hamari, "Social motivations of live-streaming viewer engagement on Twitch", Computers in Human Behavior, 84, 2018, pp. 5867.

[26] Hu, M., M. Zhang, and Y. Wang, "Why do audiences choose to keep watching on live video streaming platforms?: An explanation of dual identification framework", Computers in Human Behavior, 75, 2017, pp. 594-606.

[27] Karp, D.A. and W.C. Yoels, "Sport and Urban Life", Journal of Sport and Social Issues, 14(2), 1990, pp. 77-102.

[28] Kaye, L.K., C.R. Pennington, and J.J. McCann, "Do casual gaming environments evoke stereotype threat? Examining the effects of explicit priming and avatar gender", Computers in Human Behavior, 78, 2018, pp. 142-150.

[29] Kerr, A. and D. May, "An exploratory study looking at the relationship marketing techniques used in the music festival industry", Journal of Retail \& Leisure Property, 9(5), 2011, pp. 451-464.

[30] Kim, Y.H., D.J. Kim, and T.-M.C. Jai, "One Destination and Two Events: A Comparative Analysis on Perceived Value, Satisfaction, and Intention to Revisit", Event Management, 20(3), 2016, pp. 327-339. 
[31] Kulczynski, A., S. Baxter, and T. Young, "Measuring Motivations for Popular Music Concert Attendance", Event Management, 20(2), 2016, pp. 239-254.

[32] Lee, C.-K., Y.-K. Lee, and B.E. Wicks, "Segmentation of festival motivation by nationality and satisfaction", Tourism Management, 25(1), 2004, pp. 61-70.

[33] Lee, M.-S., D.M. Sandler, and D. Shani, "Attitudinal constructs towards sponsorship", International Marketing Review, 14(3), 1997, pp. 159-169.

[34] Li, X. and J.F. Petrick, "A Review of Festival and Event Motivation Studies", Event Management, 9(4), 2005, pp. 239-245.

[35] Lim, S., S.Y. Cha, C. Park, I. Lee, and J. Kim, "Getting closer and experiencing together: Antecedents and consequences of psychological distance in social mediaenhanced real-time streaming video", Computers in Human Behavior, 28(4), 2012, pp. 1365-1378.

[36] Macey, J. and J. Hamari, "Investigating Relationships Between Video Gaming, Spectating Esports, and Gambling", Computers in Human Behavior, 2017.

[37] Martensen, A. and L. Gronholdt, "How events work: understanding consumer responses to event marketing", Innovative Marketing, 4(4), 2008, pp. 44-56.

[38] Martensen, A., L. Grønholdt, L. Bendtsen, and M.J. Jensen, "Application of a Model for the Effectiveness of Event Marketing", Journal of Advertising Research, 47(3), 2007, pp. 283-301.

[39] Oyedele, A. and P.M. Simpson, "Streaming apps: What consumers value", Journal of Retailing and Consumer Services, 41, 2018, pp. 296-304.

[40] Pizzo, A., B. Baker, S. Na, M.A. Lee, D. Kim, and D. Funk, "eSport vs Sport: A Comparison of Spectator Motives", Sport Marketing Quarterly, 2017.

[41] Pons, F., M. Mourali, and S. Nyeck, "Consumer Orientation Toward Sporting Events", Journal of Service Research, 8(3), 2006, pp. 276-287.

[42] Ruth, J.A. and B.L. Simonin, "Brought to You by Brand A and Brand B: Investigating Multiple Sponsors' Influence on Consumers' Attitudes toward Sponsored Events", Journal of Advertising, 32(3), 2003, pp. 19-30.

[43] Salehan, M., D.J. Kim, and C. Kim, "Use of Online Social Networking Services from a Theoretical Perspective of the Motivation-Participation-Performance Framework", Journal of the Association for Information Systems, 18(2), 2017, pp. 141-172.

[44] Scheibe, K., K.J. Fietkiewicz, and W.G. Stock, "Information Behavior on Social Live Streaming Services", Journal of Information Science Theory and Practice, 4(2), 2016, pp. 6-20.

[45] Seo, W. and C. Green, "Development of the Motivation Scale for Sport Online Consumption", Journal of Sport Management, 22, 2008.

[46] Seo, Y., "Electronic sports: A new marketing landscape of the experience economy", Journal of Marketing Management, 29(13-14), 2013, pp. 1542-1560.
[47] Seo, Y. and S.-U. Jung, "Beyond solitary play in computer games: The social practices of eSports", Journal of Consumer Culture, 16(3), 2016, pp. 635-655.

[48] Steinmann, S., G. Mau, and H. Schramm-Klein, "Brand Communication Success in Online Consumption Communities: An Experimental Analysis of the Effects of Communication Style and Brand Pictorial Representation", Psychology \& Marketing, 32(3), 2015, pp. 356-371.

[49] Trail, G. and J. James, "The Motivation Scale for Sport Consumption: Assessment of the Scale's Psychometric Properties", Journal of Sport Behavior, 24, 2001.

[50] Uysal, M., L. Gahan, and B.S. Martin, "An examination of event motivations: a case study", Festival Management \& Event Tourism, 1(1), 1993, pp. 5-10.

[51] van der Heijden, "User Acceptance of Hedonic Information Systems", MIS Quarterly, 28(4), 2004, p. 695.

[52] van Hilvoorde, I. and N. Pot, "Embodiment and fundamental motor skills in eSports", Sport, Ethics and Philosophy, 10(1), 2016, pp. 14-27.

[53] Voss, G.B., A. Parasuraman, and D. Grewal, "The Roles of Price, Performance, and Expectations in Determining Satisfaction in Service Exchanges", Journal of Marketing, 62(4), 1998, p. 46.

[54] Wakefield, K.L., "The pervasive effects of social influence on sporting event attendance", Journal of Sport and Social Issues, 19(4), 1995, pp. 335-351.

[55] Wann, D.L., "Preliminary validation of the sport fan motivation scale", Journal of Sport and Social Issues, 19(4), 1995, pp. 377-396.

[56] Wann, D.L. and N.R. Branscombe, "Sports fans: Measuring degree of identification with their team", International journal of sport psychology, 24(1), 1993, S. 117.

[57] Weiss, T. and S. Schiele, "Virtual worlds in competitive contexts: Analyzing eSports consumer needs", Electronic Markets, 23(4), 2013, pp. 307-316.

[58] Wenner, L.A., "Reflections on Communication and Sport", Communication \& Sport, 1(1-2), 2013, pp. 188-199.

[59] Woosnam, K.M., J. Jiang, C.M. van Winkle, H. Kim, and N. Maruyama, "Explaining Festival Impacts on a Hosting Community Through Motivations to Attend", Event Management, 20(1), 2016, pp. 11-25.

[60] Yoshida, M. and J.D. James, "Customer Satisfaction with Game and Service Experiences: Antecedents and Consequences", Journal of Sport Management, 24(3), 2010, pp. 338-361.

[61] Yu, E., C. Jung, H. Kim, and J. Jung, "Impact of viewer engagement on gift-giving in live video streaming", Telematics and Informatics, 2018.

[62] Zhang, Y. and K.K. Byon, "Push and pull factors associated with the CTTSL game events between on-site and online consumers", International Journal of Sports Marketing and Sponsorship, 18(1), 2017, pp. 48-69. 